\title{
Stress and burnout syndrome in health professionals
}

\begin{abstract}
Introduction: Stress can lead to negative health consequences, like stress and burnout.

Objective: this study analyses the overall level of stress, the main stressors sources, and presence of Burnout syndrome.

Materials and methods: cross-sectional study, with professionals of a family health strategy of Santa Catarina, Brazil, using the instruments Maslach Burnout Inventory and the Stress Questionnaire for Health Professionals.

Results: 38 professionals participated, data show that $34 \%$ are very stressed, $61 \%$ with moderate stress and $5 \%$ with little stress. The career and remuneration were the most relevant stressors, followed by dealing with customers. The favoritism and/or discrimination at work were considered by $84 \%$ professionals as the greater generating source of stress and pressure. Results revealed that $34.2 \%$ have burnout and $8 \%$ are with high stress.

Conclusion: Considering the number of professionals affected by stress and burnout, emphasized the importance of the implementation of preventive activities that improve the well-being at work and reinforces the need for psychological monitoring to those professionals
\end{abstract}

Keywords: occupational stress, health professional, burnout syndrome, pain and death
Volume 3 Issue 5 - 2019

\author{
Fabiana Meneghetti Dallacosta \\ Department of Public Health, Universidade do Oeste de Santa \\ Catarina-Unoesc, Brazil
}

Correspondence: Fabiana Meneghetti Dallacosta, Universidade do Oeste de Santa Catarina-Unoesc, Rua Getúlio Vargas, 2125 Bairro Flor da Serra, CEP 89.600-000, Joaçaba, Brazil,Tel (49)355I-207I e 355I-2230,

Email fabiana.dallacosta@unoesc.edu.br

Received: July 03, 2019 | Published: September 19, 2019
Abbreviations: FHS, family health strategy; CHA, community health agents; MBI, maslach inventory burnout; SQHP, stress questionnaire for health professionals

\section{Introduction}

The health professional is exposed to various stressors, which sometimes overwhelm the worker and lead to negative health consequences, including substance abuse, depression and burnout. ${ }^{1}$ Researches in the area of occupational stress have been carried out in the various professional areas in order to identify stressful scenarios, symptoms and other factors, and these studies point to a considerable percentage of health professionals evidencing stress reactions that affect the their physical and mental health and jeopardize their personal well-being and their ability to provide adequate care. It is not only the organizational factors or the workplace that contribute to the stress and illness of health professionals, but also the aspects related to their type of work, since they are in constant contact with death, disease and human suffering. ${ }^{2}$ The unhealthy environment, low salaries, close contact with patients mobilizes unconscious emotions and conflicts, making these workers particularly susceptible to psychic suffering and illness due to work. ${ }^{3}$ The health professional as a caregiver under constant tension, since he deals with sick people and the feelings of impotence, frustration and failure are constant in the day to day work and can lead to exhaustion and illness.

Health professionals, especially those working in the family health strategy, face daily with various situations, together with the need to effectively deal with the needs of the user. ${ }^{4}$ In burnout syndrome, workers become affectively involved with their clients, wear out, and often the syndrome in health professionals is triggered by daily contact with suffering, pain and death, overwork, lack resources to perform their work properly; by the lack of rewards and stimuli in their activity; by intimidation of being criticized for poor performance of their work and facing ethical problems resulting from technological advancement, often making the professional see the human being only as a work tool. ${ }^{5}$ Based on this context and aiming to identify how the professionals who work in the Family Health Strategy (FHS) are, this study aimed to evaluate the levels of stress and burnout syndrome among health professionals who work in a Family Health Strategy of a city of Santa Catarina, as well as identify the main stressors.

\section{Material and methods}

This is a cross-sectional research, with a quantitative approach. The city where this study was carried out is located in the Midwest region of the State of Santa Catarina, Brazil and has approximately 10,000 inhabitants. It is attended by three teams of FHS, composed of a physician, nurse, nursing technicians, community health agents (CHA), dentists, psychologist, speech therapist, pharmacist and general service aides, totaling 49 professionals. Inclusion criterion was to be a professional of the FHS. For data collection, a questionnaire consisting of two parts was used. For the analysis of burnout, the Maslach Inventory Burnout (MBI) was used. This is a seven-point Likert scale assessment with 22 questions: nine assess emotional exhaustion, five depersonalization, and eight professional achievements, the latter subscale being the inverse score. For stress analysis, we used the Stress Questionnaire for Health Professionals (SQHP). This scale intends to evaluate the potential sources of stress in the work activity of health professionals (regardless of context, area and/or activity domain). The questionnaire comprises two distinct parts. In an initial phase, it is proposed to the professionals the evaluation of the global level of stress that they experience in their activity, through a single item $(0=$ No stress, $4=$ High stress $)$. In the second section, 25 items related to the potential sources of stress associated to the professional activity is indicated. The items 
are distributed in six subscales, being answered in a Likert scale of 5 points $(1=$ No stress, $5=$ High stress $)$. The score was obtained by adding the items of each dimension, then dividing the values found by the total of items in the respective subscale. Thus, higher values mean less perceived stress in each of the domains evaluated. The dimensions evaluated are:

I. Dealing with clients: refers to the negative feelings of professionals related to the patient. Ex: Serious customer problems, etc.

II. Excess work: it refers to excessive workload and lack of time to properly perform tasks.

III. Career and compensation: it indicates the feelings of malaise related to the lack of prospects for career development and dissatisfaction with the salary received.

IV. Professional relations: describes the discomfort of professionals regarding the work environment as well as the relationship maintained with co-workers and superiors. Eg conflicts with colleagues lack of support from superiors, etc.

V. Training actions: reports the negative experiences of the professionals in situations where they must elaborate and conduct training actions and make public presentations;

VI. Family problems: Describes family relationship problems and lack of support from significant people.

VII. Categorical variables were expressed as counts and percentages and numerical variables as mean and standard deviation.

Data collection was done after approval of the Research Ethics Committee of the University of Western Santa Catarina. The subjects signed the Informed Consent Form and participated in the study, completing the two instruments (SQHP and MBI) at a time that was most convenient for them. Professionals who did not respond to the questionnaire and those who were on vacation or leave for health treatment were excluded from the study, totaling 11 professionals.

\section{Results and discussion}

Participated 38 professionals $(77.5 \%)$, women predominated (97\%), age ranged from 25 to 55 years, with a predominance of 36 to 45 years $(67 \%)$. Regarding the professional categories surveyed, there is a predominance of community health agents $(42 \%)$, which is expected by the proportion of professionals assigned to each team, followed by Nursing Technicians (18\%), Nurses (8\%), cleaning services (8\%), Administrative Assistant (5\%), Dentist (5\%), Social Assistant (3\%), Physician (3\%), Psychologist (3\%), SpeechLanguage Pathologist (3\%), Auxiliary in Oral Health (3\%). Each FHS of the city has its multi professional team formed by a general practitioner, a nurse, two nursing technicians and six CHA, according to Administrative Rule No. 648/2006, which determines the maximum number of 750 inhabitants per Community Health Agent, being that the professionals: speech therapist, psychologist, dentist, oral health assistant, social worker and administrative assistant act concomitantly in the three FHS of the municipality.

Regarding the overall level of stress that professionals feel in the practice of their profession, it should be noted that $8 \%$ of the participants in this study reported high stress associated with the profession, $26 \%$ referred a lot of stress, $61 \%$ reported moderate stress and only $5 \%$ reported little stress. These values demonstrate the emotional demands of health professionals. In this study, the majority reported moderate stress, corroborating with Lentine ${ }^{6}$ in which $62 \%$ of the nurses, $61 \%$ of the physicians and $62 \%$ of the nursing auxiliaries reported average level of stress in their workplace, as well as in the a study of Lima, ${ }^{7}$ in which $70 \%$ of health workers presented moderate stress, followed by $23.3 \%$ intense stress and $6.66 \%$ did not present stress. If we associate high, enough and moderate stress levels, we will have $95 \%$ of stressed professionals. The fact that most health professionals are stressed causes concern about the quality of care provided and their own quality of life. In addition, it suggests that the quality of the work of these professionals may be impaired, as fatigue and physical exhaustion may be interfering with professional performance.

The dimensions that were mentioned as the most generators of stress were career and remuneration $(39 \%)$, followed by issues related to dealing with clients (34\%), professional relationships (16\%) and overwork $(11 \%)$. Discontent with career-related issues may be related to lack of prospects for progression, low pay, and lack of infrastructure to adequately perform their duties. Insufficient wages generate feelings of dissatisfaction and discouragement, and in order to increase income, professionals can choose to increase their working hours by associating more than one job, which contributes to more fatigue and risk of problems of health. ${ }^{8}$ Similar data to this had already been described by Schmidt ${ }^{9}$ when assessing the quality of life in the work of nursing professionals, from the perspective of satisfaction, verified that the low salaries of the nursing categories were pointed out as one of the causes of greater dissatisfaction.

In other studies on job satisfaction, workers' dissatisfaction with this aspect was also evident. Suehiro ${ }^{10}$ study on the vulnerability to stress and job satisfaction in professionals of the Family Health Program indicated that the issues related to financial gain and the perspective of growth within the focused health unit were those that arouse dissatisfaction in the professionals surveyed. The salary and the possibility of ascension in the work were also the variables that produced greater dissatisfaction in the nursing professionals. ${ }^{11}$ A study with 34 nurses to know the level of satisfaction of this professional class among nurses who work in home care, found that $73.53 \%$ of the nurses disagreed with the item 'My current salary is satisfactory'. ${ }^{12}$ This context can negatively influence the psychological sphere of professionals, causing suffering and illness.

The dimension of 'dealing with clients' has emerged as one of the most mentioned sources of pressure, which can be motivated by the level of demand that health professionals face, having to deal with patients and family members, often facing a feeling of impotence towards pain, illness and death. Stress studies in health professionals have shown that working with people and their relationships, especially if they present personal and family problems, can lead to stress experiences, and thedifficulty of dealing with these issues has contributed to difficult situations. ${ }^{13}$ The feeling generated by these situations often translates into exhaustion, frustration and revolt and in the study by Seemann, ${ }^{14} 11.36 \%$ of respondents reported that this factor is also a trigger for stress at work. Professionals also point out that issues related to professional relationships, such as peer relationships and leadership, are stressful. Good relationships among peers based on understanding, tolerance and the spirit of self-help can be very rewarding and contribute significantly to a good work environment favoring individual and organizational health. However, uncertain, distrustful, uncooperative and destructive relationships 
can lead to high levels of tension and stress among members of a workforce and be highly harmful to mental health. ${ }^{13}$

Data similar to this had previously been found in assessing the type of relationships at work, and revealed that individuals who claimed to have at least one co-worker their friend, both in and out of work, had significantly fewer stress experiences. ${ }^{13}$ Seemann ${ }^{14}$ in his study reports that for $32.95 \%$ of the participants this is one of the major problems of the unit because it is really very difficult to live with conflicting relationships. Competition and rivalry, coupled with lack of support in difficult situations, are the main stressors in interpersonal relationships ${ }^{13}$ Relationships with hierarchical superiors can contribute to psychological well-being or, on the contrary, be a source of stress, since it is a source of promotions, salary increase, better working conditions, as well as punishment, and a treatment based on disregard and favoritism on the part of the superior, relate positively to the tension and pressure at work. In addition, too close and too rigid leadership over subordinates' work can also result in stress. ${ }^{13}$

The health professionals in this study work as a team, and in teamwork there are some stressors, such as lack of cohesion, team pressures, group climate and conflicts between people. In this way, a weak motivation among team members reflects on the team's mood giving rise to emotional problems, which are manifested by: depression, lack of interest, apathy and dissatisfaction, and, in extreme cases, can reach aggressive states. Overwork was cited as responsible for stress for $11 \%$ of respondents, a percentage that is below the values found in the study by Lentine, ${ }^{6}$ where for $19 \%$ of nurses what causes more stress in the workplace is the high demand, as well as for $18 \%$ of physicians. In the dimensions of training actions and family relationships, no significant values were observed, which suggests that the professionals studied are qualified for their work activities and maintain a good family relationship. In a more detailed analysis of the possible problems that can contribute to stress, Table 1 illustrates the 10 sources of stress included in the second part of the SQHP that were considered to generate the greatest pressure. The 'favoritism and/or discrimination covered in my workplace', mentioned by most professionals, is highlighted, from which it can be observed that the professionals studied feel the need to be valued in their work and that they do not admit to being discriminated or deprecated The 'lack of encouragement and support from superiors' was also cited as a source of stress for most of the respondents. In the study by Lentine ${ }^{6}$ only $8 \%$ of the nurses mentioned a lack of support, motivation and leadership collection as stress-generating factors.

Table I Aspects mentioned by health professionals as generators of stress

\begin{tabular}{llc}
\hline Stress source & N & $\%$ \\
\hline Favoredness and / or discrimination "shrouded" in my workplace & 32 & 84 \\
The lack of encouragement and support from my superiors & 31 & 82 \\
Make decisions where mistakes can have serious consequences for my clients & 30 & 79 \\
Feeling that there is nothing to do to solve the problems of my clients & 28 & 74 \\
The lack of career development prospects & 27 & 7 I \\
Inadequate / insufficient salary & 25 & 66 \\
Lack of career advancement possibilities & 23 & 61 \\
Receive a low salary & 23 & 61 \\
Not being able to respond to what clients expect from me & 20 & 53 \\
Overwork & 20 & 53 \\
\hline
\end{tabular}

The high percentage of professionals who have mentioned as a source of stress 'making decisions where errors can have serious consequences for my clients' demonstrates that practitioners understand that their work activities require constant attention, and that errors are not allowed. This can be a constant source of stress because the practitioner needs to be always attentive and focused on his tasks, to avoid recklessness and mistakes that can bring harm to patients. It is found that a poor working environment, the ease of making mistakes, dealing with failures, and salary issues are the areas of stress that largely encompass the top 10 sources of stress reported by health professionals and are associated with psychological health disorders. ${ }^{15}$ These data can be explained by the fact that these professionals have a good perception of the demands of their profession, the poor salary policies of the public administrations, the expectations regarding the salary earned and the increase of the quality requirement by the clients.

Table 2 Aspects mentioned by health professionals as generators of low stress

\begin{tabular}{|c|c|c|}
\hline Stress source & $\mathbf{N}$ & $\%$ \\
\hline The lack of stability and security in my marital and / or personal life due to my professional responsibilities & 4 & 10 \\
\hline Lack of social and emotional support outside the workplace (family, friends) & 6 & 16 \\
\hline Interpersonal problems with significant / family members due to my professional responsibilities & 8 & 21 \\
\hline Carry out training activities under my responsibility & 9 & 24 \\
\hline Prepare training actions to perform in my workplace & 10 & 26 \\
\hline
\end{tabular}


In general, issues related to training actions and family problems do not seem to affect professionals so much, because of the five aspects that generate little stress, three are related to family relationships and two to training actions, which may be explained by having a good family structure confirming with the MBI in the item personal fulfillment and because the professionals do not develop activities as trainers (Table 2). An important factor was the lower score obtained by the QSPS, which refers to the 'lack of stability and security in my marital and/or personal life due to my professional responsibilities', confirming once again the $100 \% \mathrm{MBI}$. Analyzing aspects of MBI, of the 38 professionals participating in the study, 13 had high emotional exhaustion and depersonalization and reduced personal fulfillment, configuring them in burnout (34.2\%). This is an expressive and worrying number, since the syndrome affects the worker's relationships and well-being, which can have serious consequences for both the professional and the patient attended.

These data pointed to higher levels of burnout in these professionals compared to other studies involving health professionals, as reported by Trindade, ${ }^{16}$ when investigating the work stress experienced by the employees of a FHS teams identified 6,97\% affected by the syndrome, however it is below the study conducted by Martins, ${ }^{17}$ which indicated $41.6 \%$ of the professionals with the syndrome. Figure 1 shows the number of burnout professionals distributed by participating FHS. The high stress index in the FHS 1 sample may be associated with the fact that in this team, besides other health professionals, nursing technicians, nurse and physician, there was collaboration of other professionals; psychologist, dental practitioner, social worker, administrative assistant and oral health assistant, probably some of these professionals are dedicated to attending the FHS and in private practice, due to the flexibility of schedules, since several work only 20 hours in the unit. Given the data presented, it is necessary to intervene with health professionals, since burnout syndrome can be prevented through activities such as training, training and the inclusion of healthy practices that increase the quality of life of professionals, reduce the damage to their health, reflecting the quality of services provided to the population. ${ }^{4}$ It is necessary to consider that the professional affected by stress and burnout, in addition to having damages in the quality of his work, is also suffering, as he loses his interest in work, does not dedicate himself to the performance of his activities and may even present your physical health.

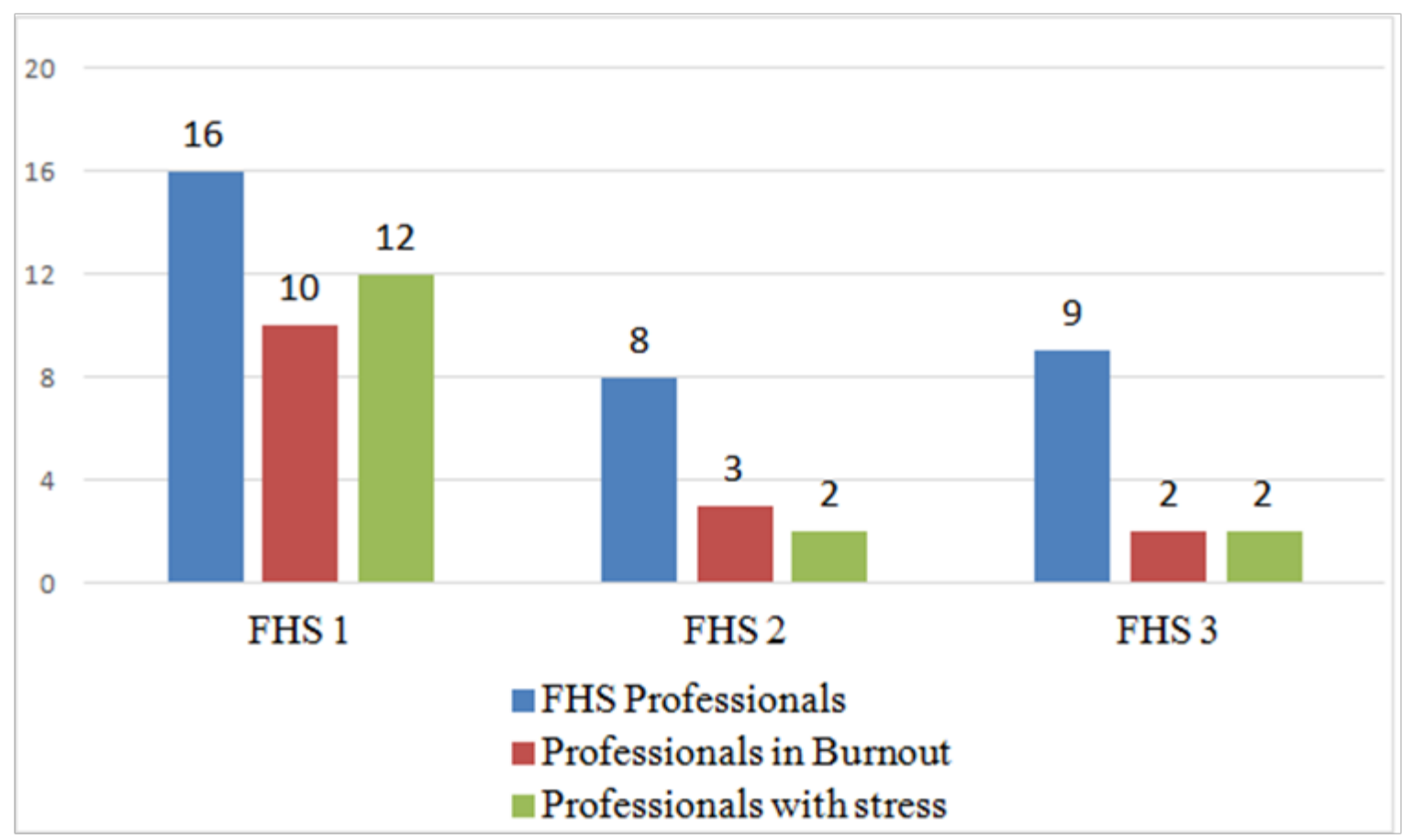

Figure I Number of burnout professionals distributed according to the FHS.

\section{Conclusion}

The study found a high prevalence of burnout and stress in health care professionals, and identified career and compensation issues as major sources of stress, followed by dealing with clients, work relationships, and overwork. As a source of stress generating greater pressure, favoritism and/or discrimination in the workplace were highlighted. These data point to a very present problem, but for which it is not given due attention, that is the psychic suffering of health professionals. Work overload, dealing daily with illness and suffering, feeling of powerlessness in the face of some problems, difficulties in interpersonal relations and low perspective of professional growth, are some causes that explain the sickness of health professionals. These feelings result in a worsening of the quality of the work done, with losses for the assisted population, in addition to generating suffering for the professional himself, which is not performed in the work and starts to see his office as a source of wear and suffering, contributing to the stress and burnout. It is important to carry out periodic actions with the health teams, in order to favor teamwork, ethics in labor relations, and implement professional valorization measures, in order to motivate the worker, since a satisfied professional with a fair remuneration and good physical and mental health, brings benefits to all staff and, especially, to the clients assisted. 


\section{Acknowledgments}

None.

\section{Conflicts of interest}

The author declares there is no conflict of interest.

\section{References}

1. Marcelino Filho A, Araújo TM. Estresse ocupacional e saúde mental dos profissionais do centro de especialidades médicas de Aracaju. Trab educ saúde. 2015;13(Supl1):177-199.

2. Lago KC,Codo W. Fadiga por Compaixão: O Sofrimento dos profissionais em saúde. $1^{\text {st }}$ edn. Petrópolis: Vozes, 2010.

3. Rios IC. Humanização e Ambiente de Trabalho na Visão de Profissionais da Saúde. Saúde e Sociedade. 2008;17(4): 51-160.

4. Ferrari R, França FM, Magalhães J. Avaliação da síndrome de burnout em profissionais de saúde. Revista Eletrônica Gestão \& Saúde. 2012;3(3):1150-165.

5. Oliveira AH. "Profissão estresse": a síndrome de burnout na enfermagem. Revista Letrando. 2013;3:1-6.

6. Lentine EC, Sonoda TK, Biazin DT. Estresse de profissionais de saúde das unidades básicas do município de Londrina. Rev Terra e Cultura. 2003;37:103-112.

7. Lima FB. Stress, qualidade de vida, prazer e sofrimento no trabalho de call center. Dissertação (Pós- Graduação em Psicologia) PUCCampinas 2004. P. 1-133.

8. Barbosa A. Implicações dos baixos salários para o trabalho dos professores brasileiros. Revista Educação e Políticas em Debate. 2012;2(2):1-3.
9. Schmidt DRC, Dantas RAS. Qualidade de vida no trabalho de profissionais de enfermagem, atuantes em unidades do bloco cirúrgico, sob a ótica da satisfação. Revista Latino-Americana de Enfermagem. 2006;14(1):54-60.

10. Suehiro ACB, Acácia Aparecida, Clarice Tsuguico, et al. Vulnerabilidade ao estresse e satisfação no trabalho em profissionais do Programa de Saúde da Família. Boletim de Psicologia. 2008;58(129):205-218.

1. Kovács MJ. Sofrimento da equipe de saúde no contexto hospitalar: cuidando do cuidador profissional. O Mundo da Saúde. 2010;34(4):420 429.

11. Paiva FFS, Rocha AM, Cardoso LDF. Satisfação profissional entre enfermeiros que atuam na assistência domiciliar. Revista escola de enfermagem. 2011;45(6):1452-1458.

12. Martins MCA. Situações Indutoras de Stress no Trabalho dos Enfermeiros em ambiente hospitalar. Millenium - Revista Instituto Superior Politécnico de Viseu. 2003;28.

13. Seemann S, Garcez EMS. O adoecimento psíquico em profissionais da enfermagem. Revista Saúde Pública Santa Catarina. 2012;5(2):46-71.

14. Gomes AR, Cruz JF, Cabanelas S. Estresse ocupacional em profissionais de saúde: Um estudo com enfermeiros portugueses. Psicologia: Teoria e Pesquisa. 2009;25(3):307-318.

15. Trindade LL, Lautert L. Estresse e síndrome de burnout entre trabalhadores da equipe de Saúde da Família. Revista da Escola de Enfermagem da USP. 2010;23(5):684-689.

16. Martins LF, Tamires Jordão, Vinicius de Paula, et al. Esgotamento entre profissionais da Atenção Primária à Saúde. Ciência \& saúde coletiva. 2014;19(12):4739-4750. 